\title{
APPLICATION OF FOREBODY STRAKES FOR DIRECTIONAL STABILITY AND CONTROL OF TRANSPORT AIRCRAFT
}

\author{
Gautam H. Shah* \\ NASA Langley Research Center \\ Hampton, VA \\ J. Nijel Granda ${ }^{\dagger}$ \\ The Boeing Company \\ Long Beach, CA
}

\begin{abstract}
A brief overview of a cooperative NASA/Boeing research effort, Strake Technology Research Application to Transport Aircraft (STRATA), intended to explore the potential of applying forebody strake technology to transport aircraft configurations for directional stability and control at low angles of attack, is presented. As an initial step in the STRATA program, an exploratory wind-tunnel investigation of the effect of fixed forebody strakes on the directional stability and control characteristics of a generic transport configuration was conducted in the NASA Langley 12Foot Low-Speed Wind Tunnel. Results of parametric variations in strake chord and span, as well as the effect of strake incidence, are presented. The use of strakes for yaw control is also discussed. Results emphasize the importance of forebody/fuselage crossflow in influencing strake effectiveness. Strake effectiveness is also seen to be directly related to its span, but less sensitive to chord; a very short-chord strake with sufficient span can have a significant effect.
\end{abstract}

\section{INTRODUCTION}

Vertical tail sizing requirements for conventional transport aircraft are often based on critical asymmetric flight conditions, such as engine thrust loss

\footnotetext{
*Aerospace Engineer, Vehicle Dynamics Branch Senior Member, AIAA

${ }^{\dagger}$ Engineer/Scientist - Stability, Control, and Flying Qualities, Phantom Works
}

Copyright (c) 1998 by the American Institute of Aeronautics and Astronautics, Inc. No copyright is asserted in the United States under Title 17, U.S. Code. The U.S. Government has a royalty-free license to exercise all rights under the copyright claimed herein for Governmental Purposes. All other rights are reserved by the copyright owner. during take-off, or high-crosswind landings. The resulting requirement for large vertical fin and rudder area can exact a large cruise drag penalty, with an associated increase in fuel cost. Therefore, alternate methods which can provide the required directional stability and control during such critical situations without resorting to large vertical tail/rudder area would be of great interest to aircraft manufacturers.

The use of forebody strakes for directional control of high-performance aircraft at high angles of attack has been studied for quite some time, including ground and flight testing within NASA's High-Angleof-Attack Technology Program (HATP). At high angles of attack (typically, $\alpha>30^{\circ}$ ), crossflow on the forebody is substantial, and altering that flowfield can generate a significant amount of side force. The large moment arm between the forebody and the center of gravity results in that side force creating large yawing moments. Substantial amounts of directional control power using strakes at high angles of attack has been demonstrated in flight as part of the HATP ${ }^{1,2}$. In light of these favorable results, a cooperative research effort was initiated between NASA Langley Research Center and McDonnell Douglas Corporation (now Boeing) to investigate the potential of applying strake technology to transport aircraft configurations. Unlike fighter aircraft, the typical operational angle of attack range for transport aircraft is well below $20^{\circ}$, with approach alphas typically in a range around $8^{\circ}$. There is substantially less crossflow on the fuselage at these conditions, so more innovative applications of strake concepts which are effective at high- $\alpha$ may be required. The use of strakes on transport aircraft is not without precedent. For example, the McDonnell Douglas DC-9 aircraft, when stretched from the Series -30 to the Series -50 configuration, incorporated small fixed strakes near the nose, reportedly to offset the change in directional stability caused by the increased fuselage length ahead of the center of gravity. These strakes were subsequently also placed on the DC-9-80, or MD-80, aircraft. However, the flow physics responsible for the directional stability changes due to 
the strakes has not been well studied, nor was the study to optimize strake size and location well documented.

\section{OVERVIEW OF STRATA PROGRAM}

The Strake Technology Research Application to Transport Aircraft (STRATA) program was developed as a four-year cooperative research effort between NASA and Boeing to explore the potential of applying forebody strake technology to transport aircraft configurations for directional stability and control at low angles of attack (typically $15^{\circ}$ and below).

As stated earlier, a detailed study to understand the flow-field characteristics responsible for the directional stability improvements due to the DC-9 strakes has not been conducted. One of the goals of the STRATA program is to address this shortcoming in the current body of knowledge. Other objectives are a better understanding of the general forebody/fuselage flow characteristics of conventional transport aircraft, and development of concepts to exploit such flow physics for improved directional stability and control during various critical flight conditions, such as crosswind approaches, engine-out conditions, and high-speed ground handling.

The technical approach is to begin with a series of exploratory wind- and water-tunnel tests of generic transport configurations to identify flow characteristics and evaluate the effectiveness of various strake or other forebody control concepts on directional axis aerodynamics. This effort will be augmented with analytical studies using a panel method approach.

As favorable or promising concepts are identified, more detailed studies (both experimental and analytical) will be performed on specific aircraft configurations. Emphasis will be placed on stability and control issues, such as control linearity, aerodynamic coupling between axes, and aerodynamic damping in all axes, with a view toward development of effective, low-angle-of-attack directional control devices for transport aircraft which would allow rudder/vertical tail size reductions for future aircraft designs.

The initial wind tunnel and water tunnel investigations have been completed; results are being reviewed to determine the nature of follow-on testing.

\section{CURRENT INVESTIGATION}

As a starting point for the STRATA program, an exploratory investigation was conducted in the NASA Langley 12-Foot Low-Speed Wind Tunnel to study the effect of fixed forebody strakes on the directional stability and control of a generic transport aircraft configuration. The nominal strake configuration used in this study was based on the fuselage strakes of the MD-80. Variations in strake planform geometry and incidence were studied. The effectiveness of a single strake as a control effector was also addressed. Results of this initial wind-tunnel study are presented herein.

\section{SYMBOLS AND ABBREVIATIONS}

b Wing span

$\overline{\mathbf{c}} \quad$ Wing mean aerodynamic chord

$\mathrm{C}_{\mathrm{L}} \quad$ Lift coefficient

$\mathrm{C}_{l_{\beta}} \quad$ Dihedral effect

$\mathrm{C}_{\mathrm{m}} \quad$ Pitching moment coefficient at $0.25 \overline{\mathrm{c}}$

$\mathrm{C}_{\mathrm{n}} \quad$ Yawing moment coefficient, body axis

$\mathrm{C}_{\mathrm{n} \beta} \quad$ Static directional stability, body axis

$\mathrm{S} \quad$ Wing reference area

X Strake chord

Y Strake span

$\alpha \quad$ Angle of attack

$\beta \quad$ Angle of sideslip

The stability derivatives, $\mathrm{C}_{l_{\beta}}$ and $\mathrm{C}_{\mathrm{n}_{\beta}}$, were computed as the slope between the rolling or yawing moment values at $\beta=+5^{\circ}$ and $-5^{\circ}$; the moments were observed to be generally linear within this range.

\section{MODEL AND FACILITY DESCRIPTION}

The model used in this investigation was a generic commercial transport configuration with lowmounted swept wings and a conventional tail arrangement (figure 1). No engine nacelles or pods were modeled. The fuselage diameter and length, as well as wing geometry, were roughly in proportion to an $8 \%$ MD-80 configuration, although the whole model is considerably different from an actual MD-80 (most notably, a conventional tail as opposed to the MD-80 T-tail, and no engines), and is not intended to represent any specific airplane type.

The forebody strakes studied during this test were based on the planform and location of those on the MD- 80 , and scaled to $8 \%$ of full-scale. The strakes were mounted normal to the fuselage surface at an azimuthal location of $60^{\circ}$ from the fuselage lowersurface centerline. Figure 2 shows the dimensions of the strakes tested, as well as their mounting position.

Tests were conducted in the NASA Langley 12-Foot Low-Speed Wind Tunnel at a nominal dynamic pressure of 4 psf, which corresponds to a Reynolds Number of $0.335 \times 10^{6}$, based on mean aerodynamic chord. Six-component force and moment data were acquired with an internally-mounted strain-gage balance. Figure 3 shows the model installation arrangement in the wind tunnel test section. 


\section{DISCUSSION OF RESULTS}

\section{STABILITY}

The effect of the baseline strakes on the basic aerodynamic characteristics is shown in figure 4 . Minor effects are seen on lift and pitching moment characteristics; namely, an increase in pitching moment due to the strakes' surface area and location well forward of the center of gravity. There is no significant effect of the strakes on the configuration's effective dihedral, or static lateral stability, except for a stabilizing influence at angles of attack above $18^{\circ}$. However, an increase in directional stability of $20 \%$ or greater is seen for $\alpha=7^{\circ}$ and higher, although little effect is seen at lower angles of attack.

Yet-unpublished water tunnel studies of this same configuration indicate that the strakes alter the fuselage crossflow characteristics in sideslip over a large length of the forward fuselage. Although the actual amount of crossflow may be small, the integrated effect over a long fuselage results in a noticeable directional stability change.

Strake effectiveness at sideslip is shown in figure 5. At low angles of attack, virtually no effect is seen across the whole sideslip range. As alpha is increased, a stabilizing yawing moment increment due to the strakes becomes evident at large beta, and the sideslip angle at which the strakes become effective decreases as angle of attack is increased. This would indicate that a critical level of crossflow is required for the strakes to have an effect. An attempt was made to quantify the required crossflow level by averaging the positive and negative sideslip angle at which the strakeon and strake-off data points no longer coincided.

Figure 6 shows the variation in this 'threshold' sideslip as a function of angle of attack. It should be noted that since only a limited amount of data were acquired during this test, repeat data points and finer angle-of-attack increments are required before adequate quantitative confidence can be placed in the figure; however, useful qualitative trend information is provided.

Figure 7 shows the effect of a single strake on the left side of the fuselage in comparison with the earlier two-strake data. At positive sideslip, the single strake generates the same yawing moment increment as two strakes, but has no effect at negative sideslip. This indicates that the leeward strake is responsible for the flowfield changes that affect directional stability; the windward strake has negligible contribution.

\section{Span and Chord Effects}

The effect of varying strake span by $50 \%$ from the baseline geometry is shown in figure 8 . The minimum angle of attack at which the strakes become effective was unchanged. The 'threshold' beta as discussed above was also unchanged for the variations. Span variation results in a stability change over the entire angle of attack range where the baseline strake itself is effective. The effectiveness due to span is roughly proportional to the span variation near stall $\left(10^{\circ}<\alpha<15^{\circ}\right)$, but less sensitive to span at higher angles of attack.

The effect of varying strake chord by $50 \%$ from the baseline geometry is shown in figure 9 . The sensitivity to this range of chord variation is significant around stall angles of attack, but is negligible above $\alpha=17^{\circ}$. Although stability levels do vary somewhat in relation to the chord length in the $7^{\circ}$ to $17^{\circ}$ range, the effect is far less than proportional; the results led to an investigation of even smaller strake chord lengths. Figure 10 shows the effect of reducing chord length to as low as one-eighth of the baseline while retaining the same span. The results clearly indicate that even a very short-chord strake can generate directional stability improvements, and a moderately-sized one can retain much of the benefit seen by the baseline strake. The effect of span on the shorter-chord strakes was not studied; therefore no conclusions about the proportional effect of span variation can be applied to these configurations.

In the cases of both chord and span variation, the impact on longitudinal characteristics as well as dihedral effect was minor.

\section{$\underline{\text { Strake Incidence Effects }}$}

The effect of strake incidence is shown in figure 11. Positive incidence angle had a minor effect on directional stability. There is a slight increase in stability for $10^{\circ}$ of incidence, but that improvement diminishes at higher incidence angles, where the effect is the same as the baseline strake. There is, however, a significant and non-linear effect due to negative incidence. In all cases, nose-down strake incidence degrades directional stability. There is only a slight loss in stability (relative to the baseline strake) at $-10^{\circ}$ incidence, but stability is significantly reduced at greater negative incidence angles, and is even worse than the strake-off configuration at low angles of attack.

\section{CONTROL}

The effectiveness of a single left strake as a directional control device can be seen in figure 12 , which shows the effect of a baseline and double-span strake on yawing moment at zero sideslip. A yawing moment increment in a direction opposite of the strake can be seen for $\alpha>10^{\circ}$. The levels are extremely low relative to those which can be generated by a conventional rudder; however, the control power may be 
sufficient for applications where small levels of yaw control are needed, such as for stability augmentation, like a yaw damper. This concept was studied by exploring if the yawing moment could be modulated with strake incidence. The results are shown in figure 13. Similar to what was seen with two symmetric strakes, there is little effect of positive incidence, but a degrading effect can be seen at negative incidence. The variation in effective angle of attack range and magnitude of yawing moment due to incidence, however, is extremely non-linear, making any application as a control device more difficult and complex than a conventional controller like a rudder. Control effectiveness at sideslip was not investigated.

The use of two, differentially-deflected strakes to increase control effectiveness was also briefly explored, but no conclusive results were found. A detailed study on the effect of incidence with this and other strake configurations is warranted, particularly if a more linear effect of incidence through differential deflection can be obtained. However, the dependency of strake effectiveness on crossflow may limit the total magnitude of control power, and hence the application of this particular strake concept as a control effector.

\section{SUMMARY OF RESULTS}

The results of this exploratory test can be summarized as follows:

1. A set of baseline strakes similar in planform and location to those on the MD-80 aircraft resulted in improved static directional stability on this generic transport configuration. As angle of attack increased, the sideslip angle at which the strakes became effective decreased, indicating that a critical level of fuselage crossflow is required for the strakes to have an effect.

2. The leeward strake is responsible for altering the flowfield which results in improved stability; the windward strake has negligible effect.

3. Directional stability improvement is roughly proportional to the span of the strake.

4. The effect of strake chord on stability is non-linear; most of the effectiveness above stall $\alpha$ can be achieved with a strake with small chord.

5. There is minimal effect of positive (nose-up) strake incidence on stability, but negative incidence has a non-linear and degrading effect.
6. The effectiveness of single or differentially-deflected strakes as a directional control device was small and very nonlinear; however, only a limited investigation was conducted in this area.

7. The forebody strakes are de-coupled control effectors-- very little impact on static longitudinal and lateral characteristics was seen.

\section{CONCLUDING REMARKS}

Results of this initial, exploratory investigation indicate that the use of strakes on transport aircraft configurations can have a noticeable effect on directional stability. The effectiveness of even very small strakes means that such a concept could be applied with perhaps only minor impacts on drag and performance. The requirement for minimum levels of crossflow, however, could mean that direct application of this strake concept may not be of great benefit in development of a control effector.

Recognizing the ability to alter the fuselage flowfield with relatively small surfaces, whether fixed or actuated, at low angles of attack should hopefully spur greater research toward the understanding of the flowfield behaviors that impact lateral/directional characteristics of transport aircraft. The STRATA program will continue along this course in improving flowfield understanding and in the development of innovative control effectors for transport aircraft configurations.

\section{REFERENCES}

1. Murri, D.G.; Fisher, D.F.; and Lanser, W.R.: Flight-Test Results of Actuated Forebody Strake Controls on the F-18 High-Alpha Research Vehicle. NASA CP-1998-207676, Part 2, June, 1998.

2. Fisher, D.F.; Murri, D.G.; and Lanser, W.R.: Effect of Actuated Forebody Strakes on the Forebody Aerodynamics of the NASA F-18 HARV. NASA CP-1998-207676, Part 2, June, 1998.

3. Lin, J.C.; Robinson, S.K.; McGhee, R.J.; and Valarezo, W.O.: Separation Control on High Reynolds Number Multi-Element Airfoils. AIAA92-2636, June, 1992. 


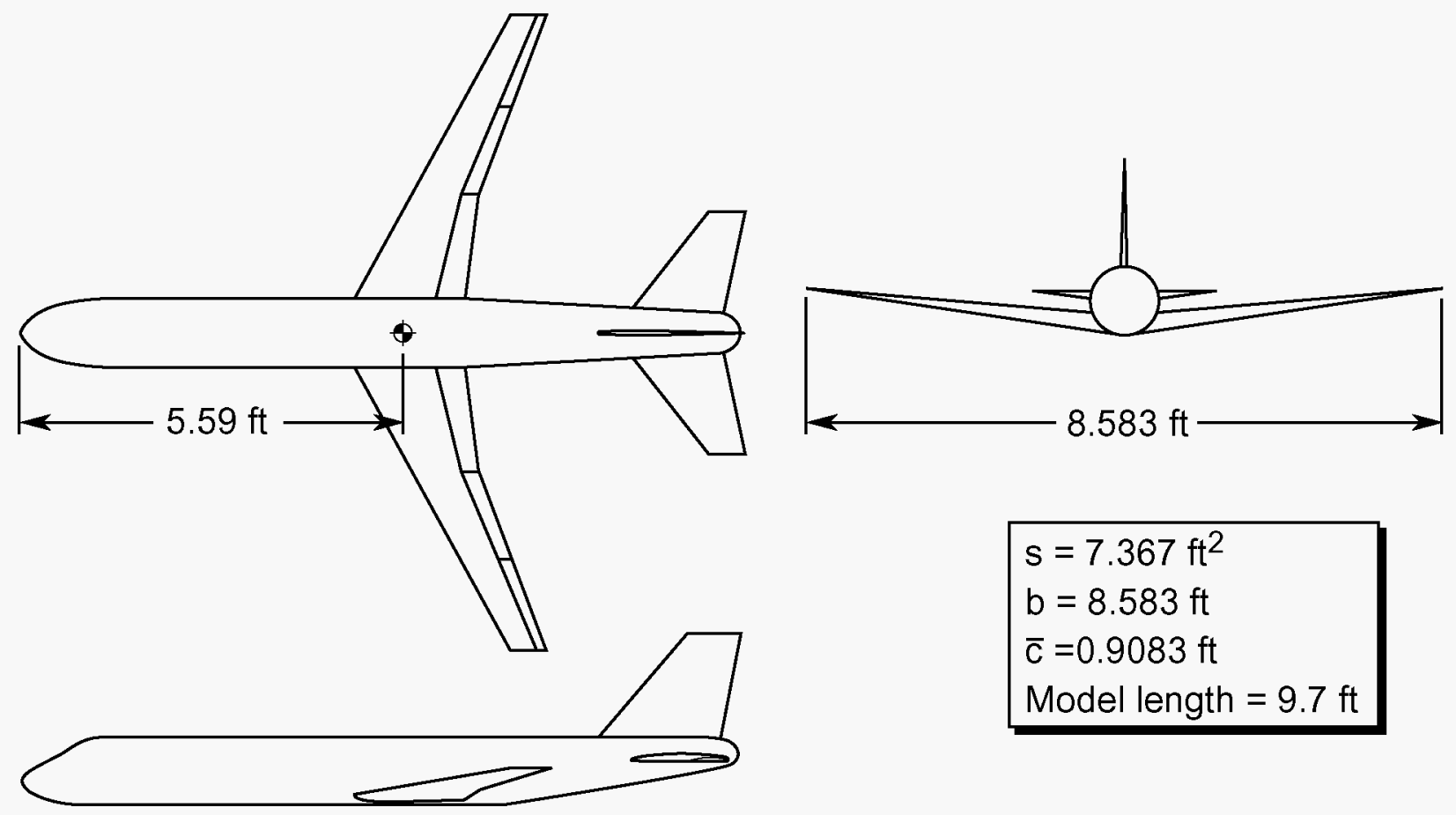

Figure 1. Generic transport configuration geometry (not to scale)



\begin{tabular}{|lcc|}
\hline Strake & X(in.) & $Y$ (in.) \\
\hline Baseline & 4.0 & 0.5 \\
Span Variation & 4.0 & 0.25 \\
Span Variation & 4.0 & 0.75 \\
Span Variation & 4.0 & 1.0 \\
Chord Variation & 0.5 & 0.5 \\
Chord Variation & 1.0 & 0.5 \\
Chord Variation & 2.0 & 0.5 \\
Chord Variation & 6.0 & 0.5 \\
\hline
\end{tabular}

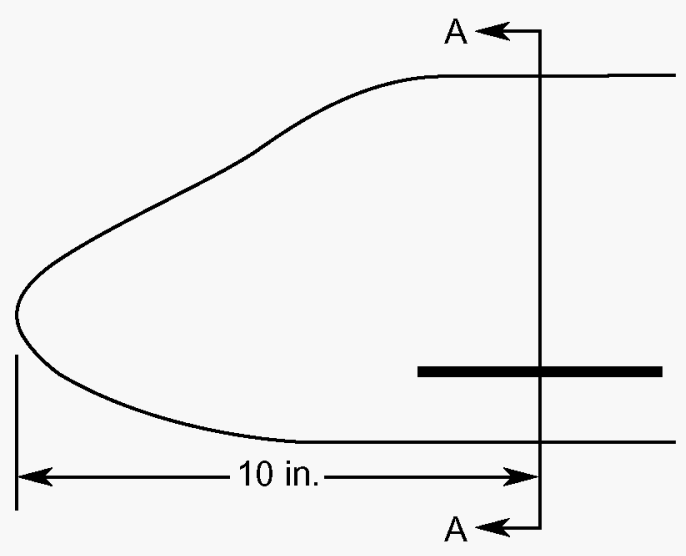

Figure 2a. Strake geometry details

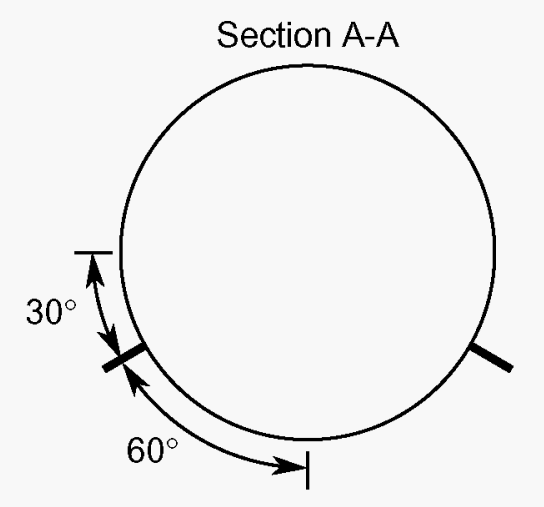

Figure $2 b$. Strake position details 
AIAA-98-4448

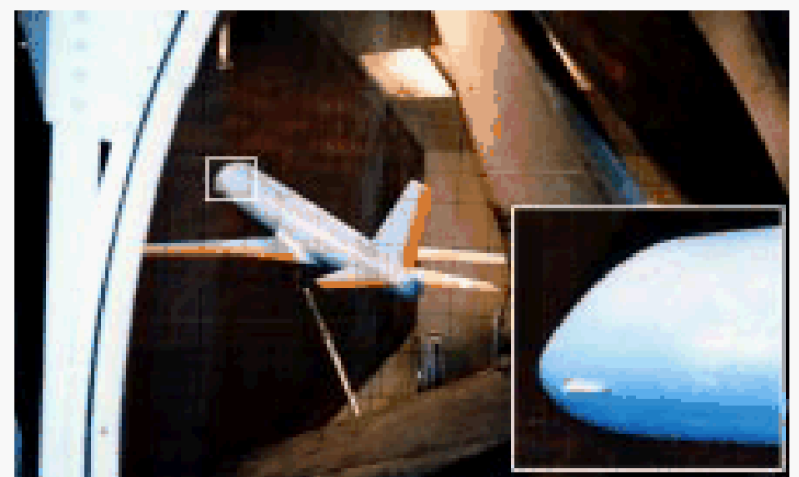

Figure 3. Generic transport model in the NASA Langley 12-Foot Low-Speed Wind Tunnel

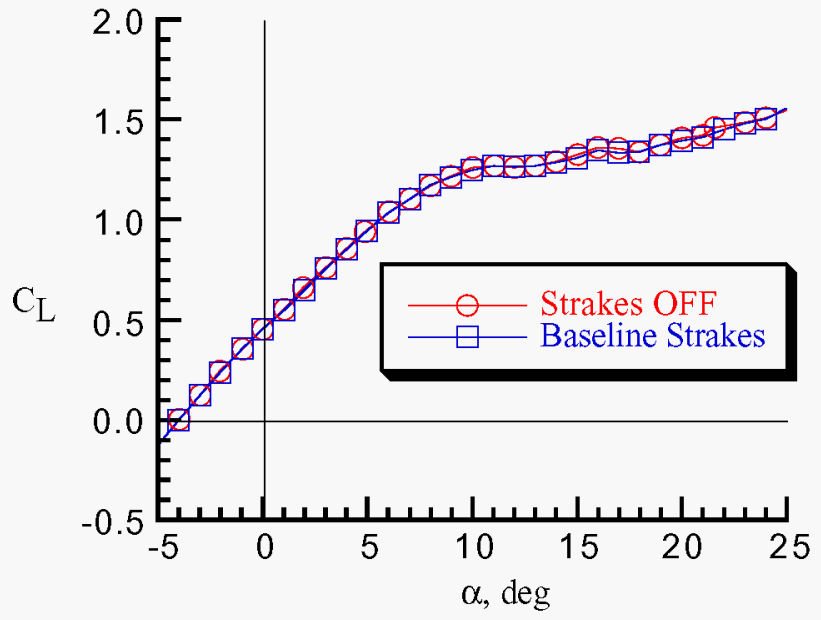

Figure 4a. Baseline strake effect on lift

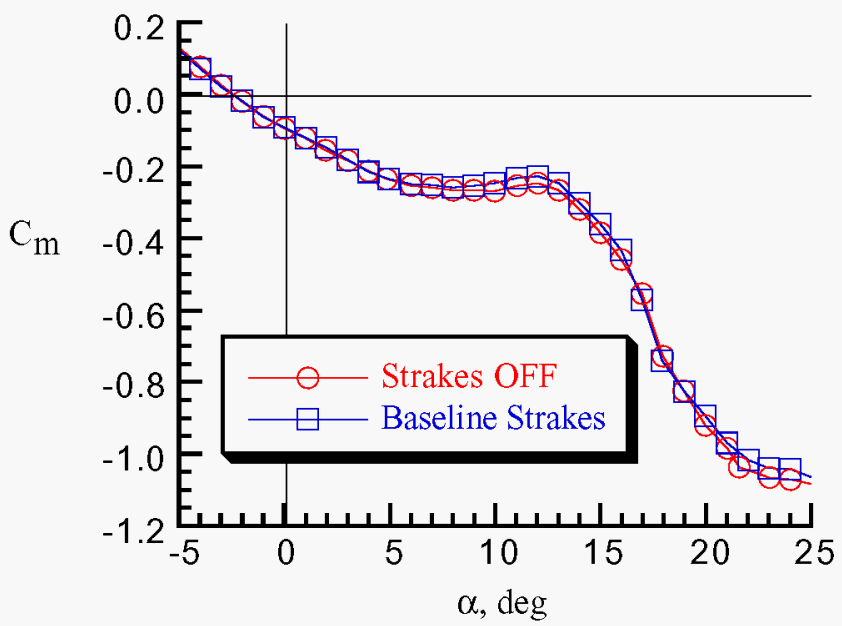

Figure $4 \mathrm{~b}$. Baseline strake effect on pitching moment

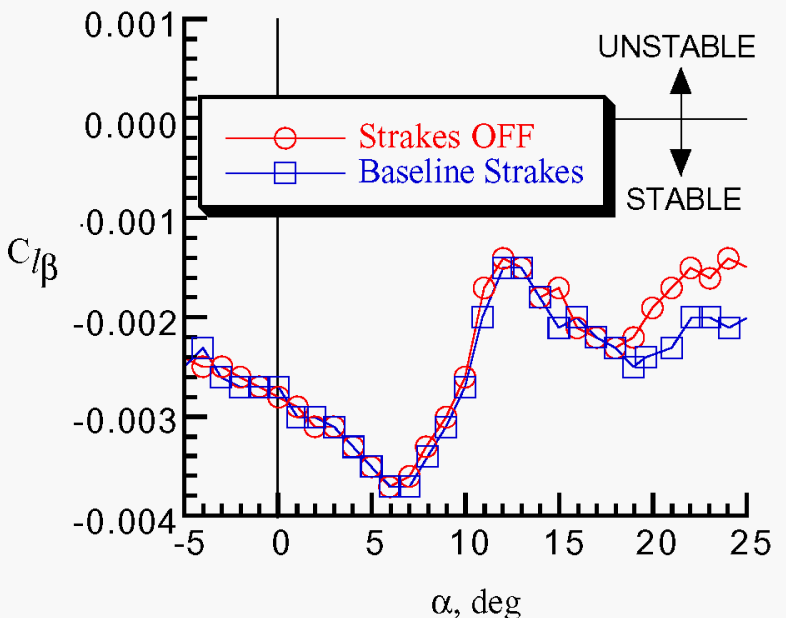

Figure $4 \mathrm{c}$. Baseline strake effect on lateral stability

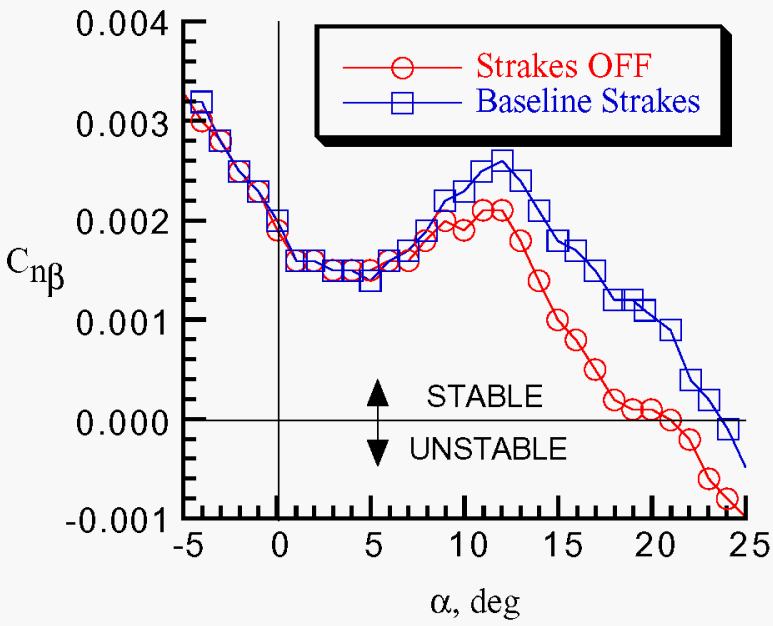

Figure $4 \mathrm{~d}$. Baseline strake effect on directional stability

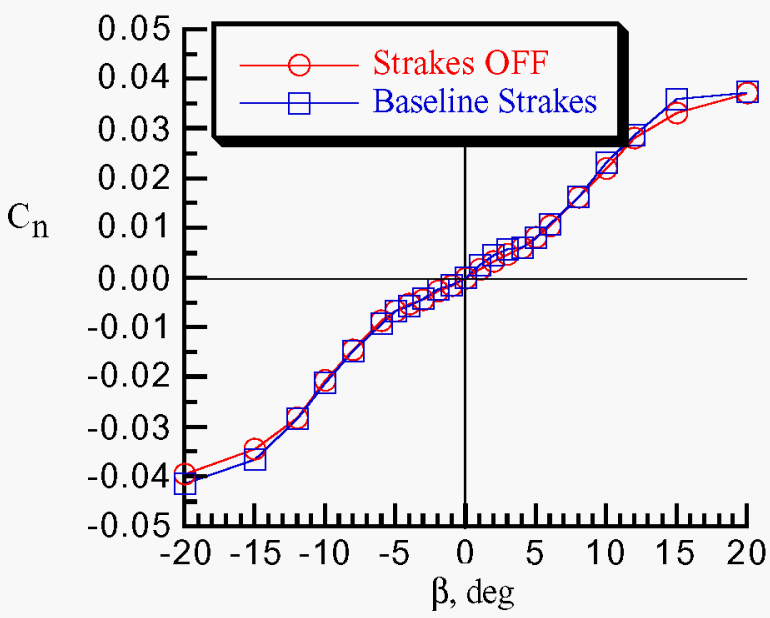

Figure 5a. Baseline strake effect, $\alpha=4^{\circ}$ 


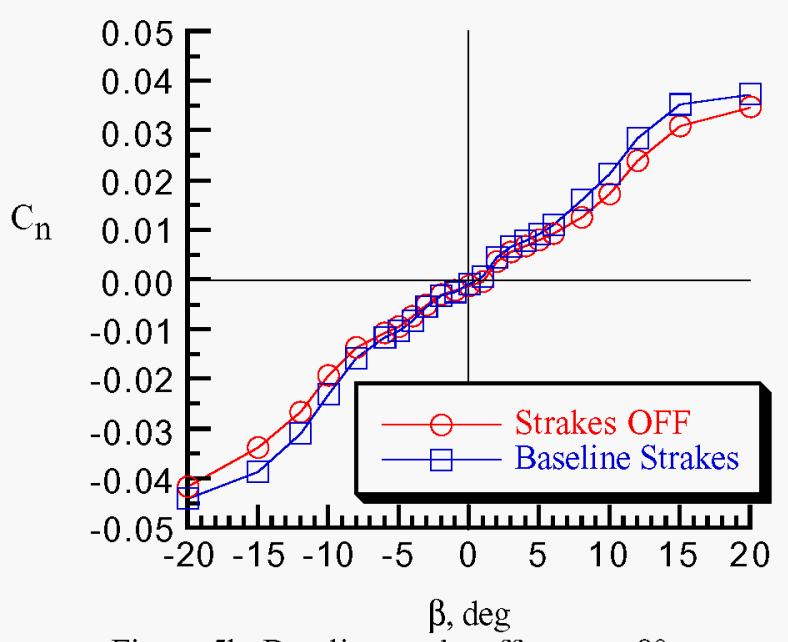

Figure 5b. Baseline strake effect, $\alpha=8^{\circ}$

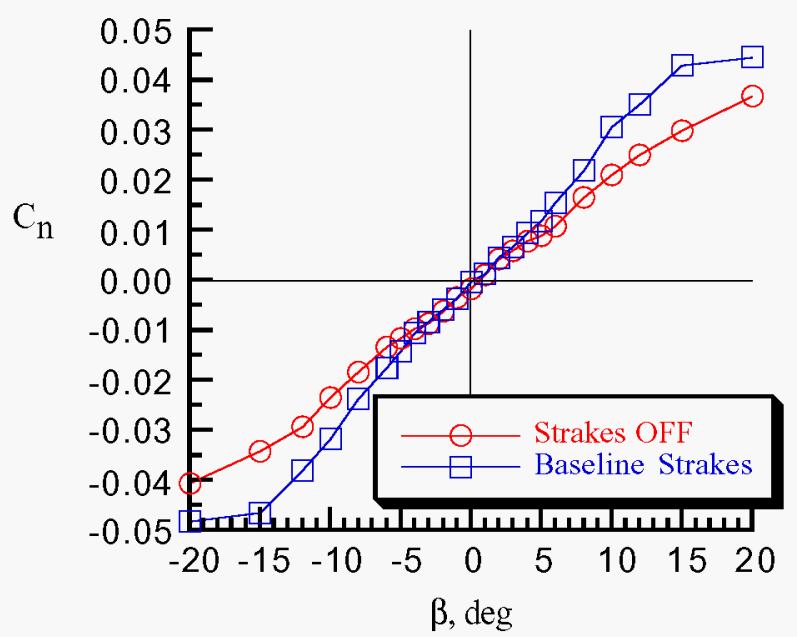

Figure $5 \mathrm{c}$. Baseline strake effect, $\alpha=12^{\circ}$

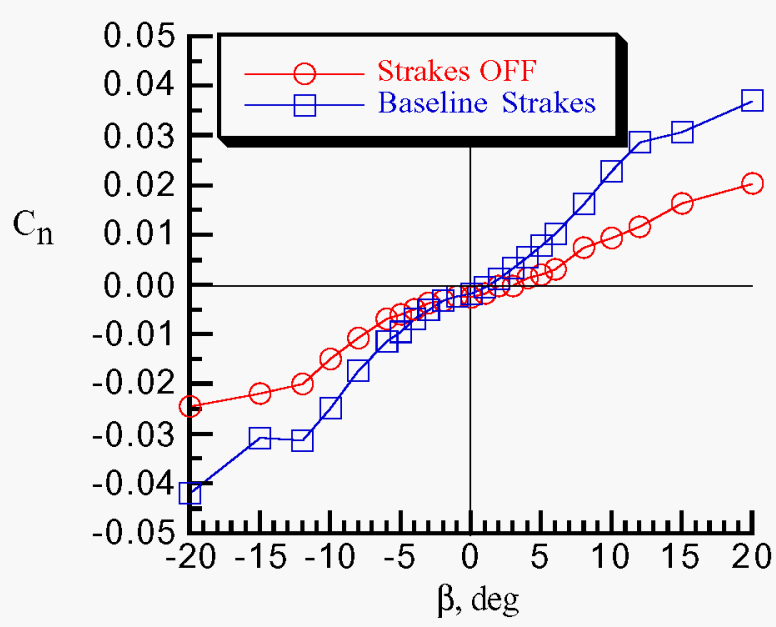

Figure $5 \mathrm{~d}$. Baseline strake effect, $\alpha=16^{\circ}$

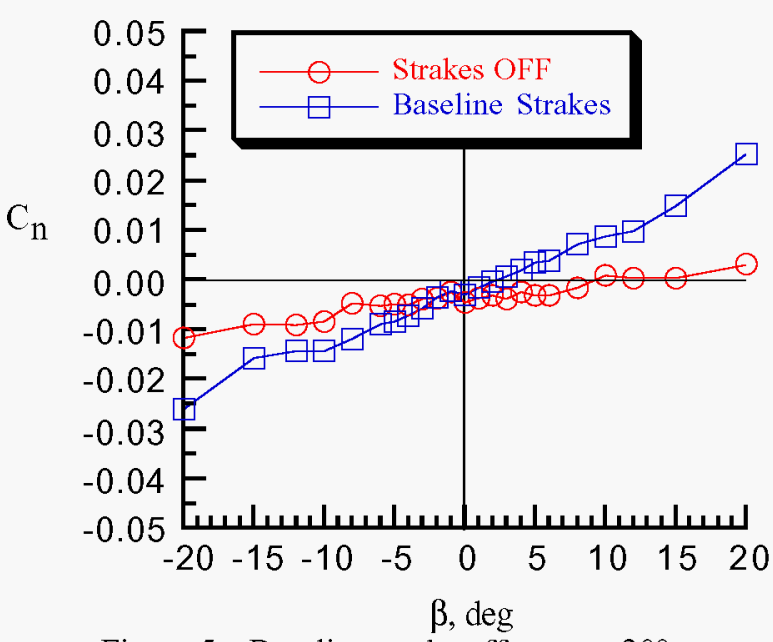

Figure 5e. Baseline strake effect, $\alpha=20^{\circ}$

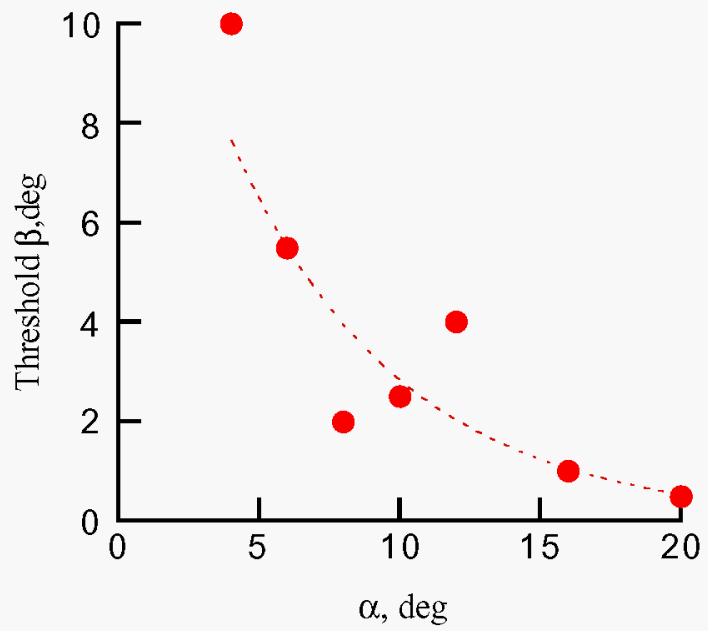

Figure 6. 'Threshold' sideslip for strake effectiveness

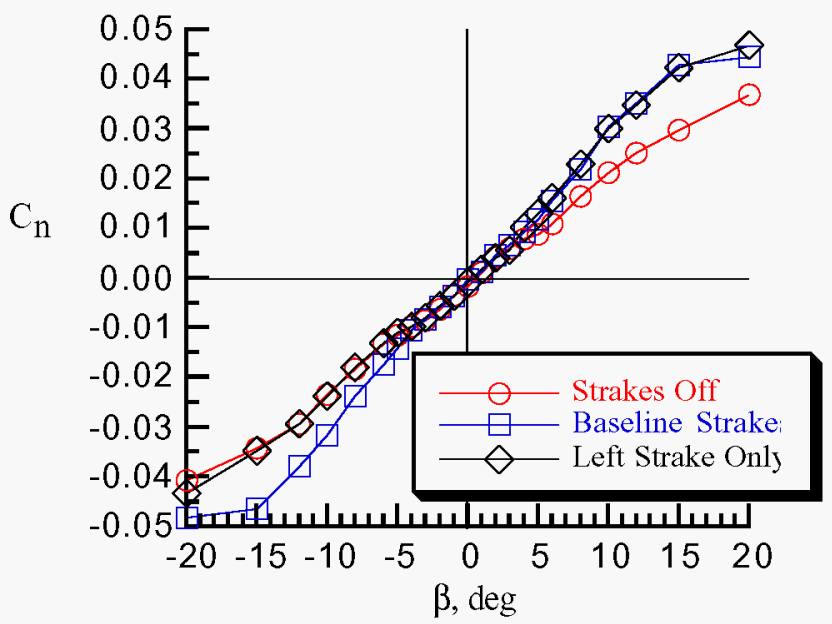

Figure 7. Effect of single versus two strakes, $\alpha=12^{\circ}$ 


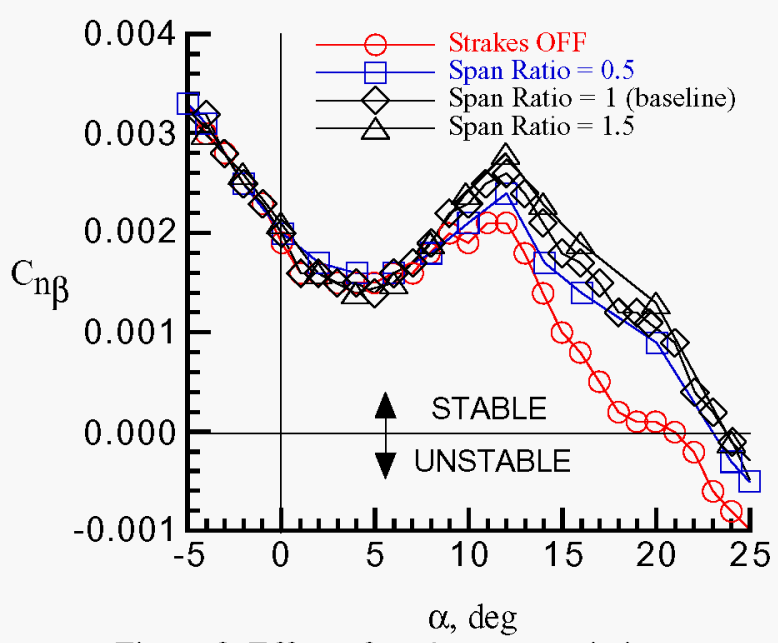

Figure 8. Effect of strake span variation

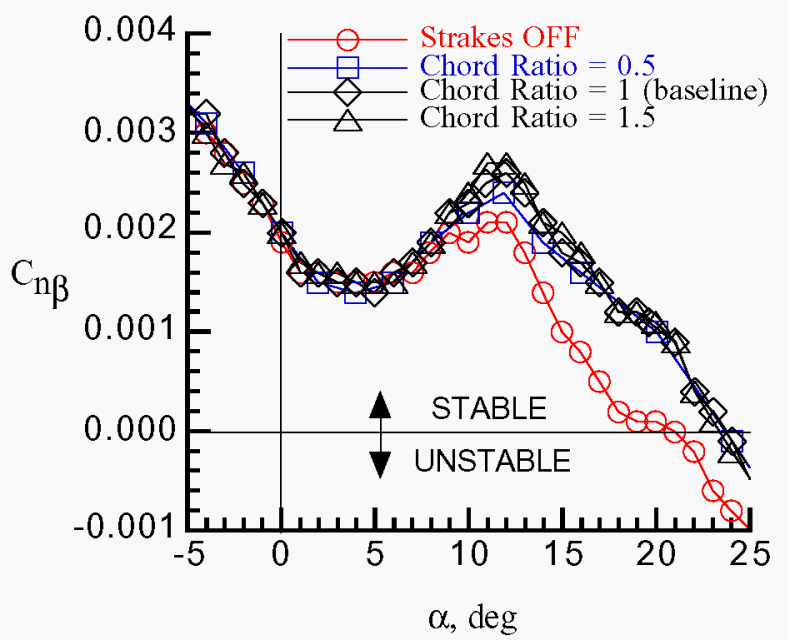

Figure 9. Effect of strake chord variation

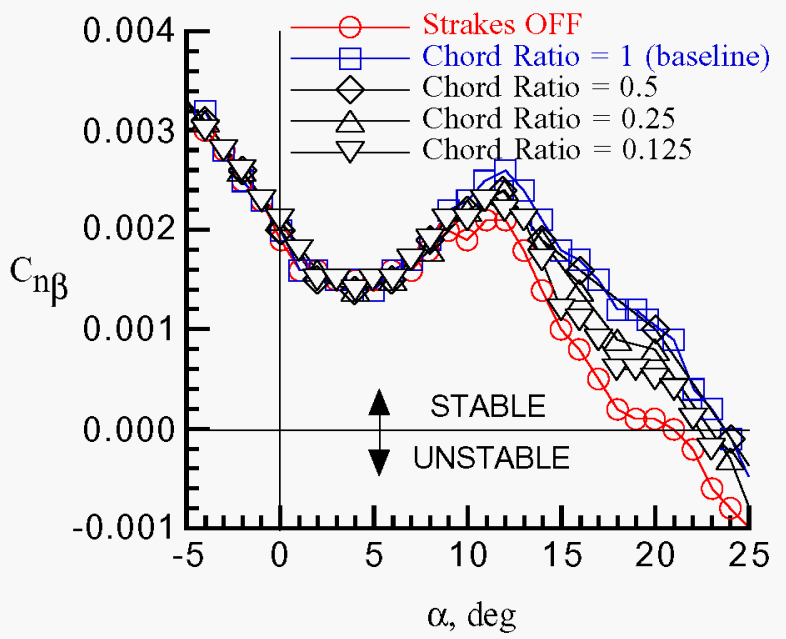

Figure 10. Effect of reducing strake chord

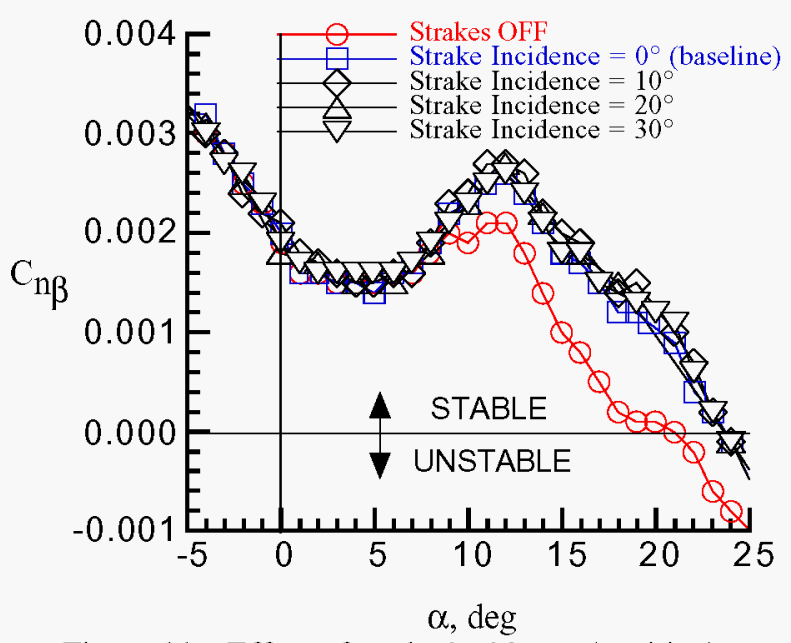

Figure 11a. Effect of strake incidence (positive)

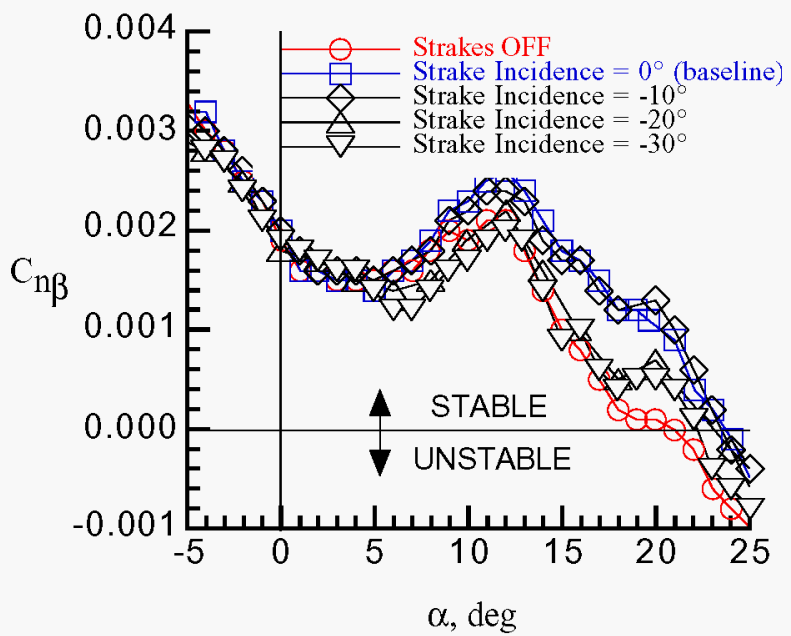

Figure 11b. Effect of strake incidence (negative)

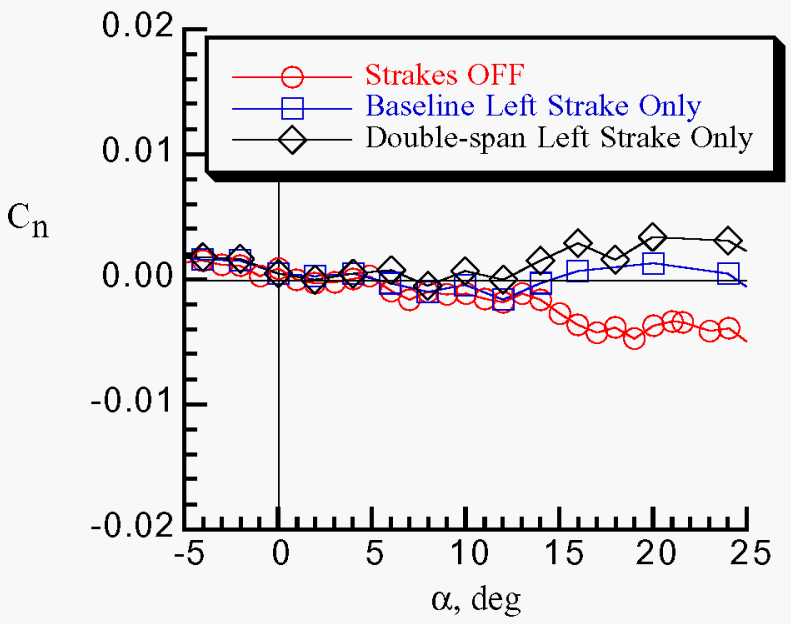

Figure 12. Effect of single strake on yawing moment 


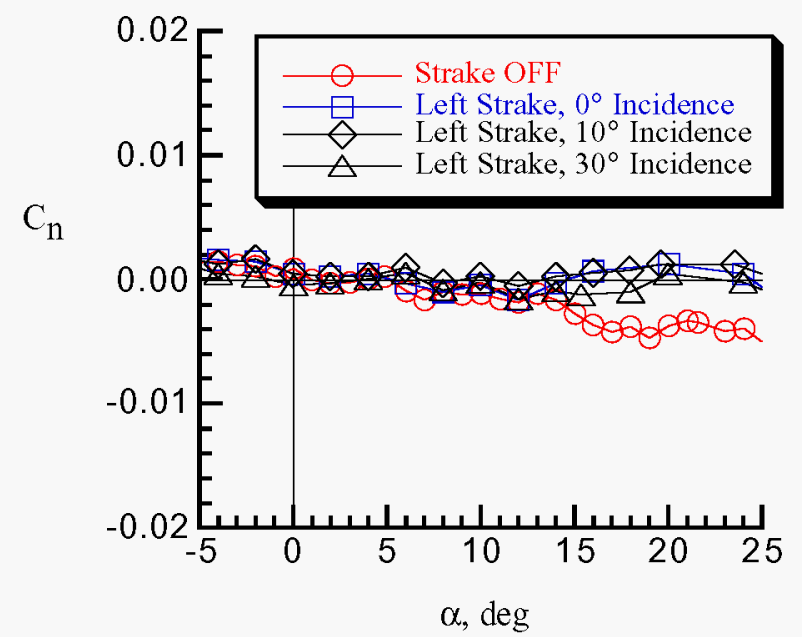

Figure 13a. Effect of left strake incidence on yaw control (positive incidence)

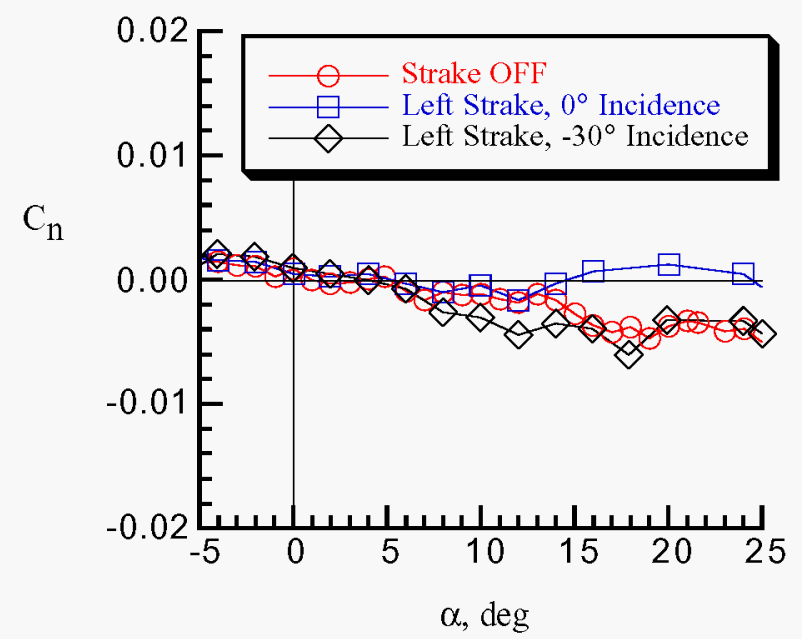

Figure 13b. Effect of left strake incidence on yaw control (negative incidence) 